ORIGINAL ARTICLE

\title{
Current practice of sexual history taking by sexual health physicians in Australia and New Zealand
}

\author{
R L Tideman, M K Pitts, C K Fairley
}

Sex Transm Infect 2004;80:389-391. doi: 10.1136/sti.2003.007559

See end of article for authors' affiliations .....................

Correspondence to: Dr Robin Tideman, Melbourne Sexual' Health Centre, 580 Swanston Street, Vic 3053, Australia; rtideman@mshc. org.au

Accepted for publication 7 January 2004

\begin{abstract}
Objectives: To document the current practice of fellows of the Australasian College of Sexual Health Physicians (ACSHP) when taking a sexual history from a new client.

Method: A postal questionnaire was sent to all eligible fellows practising sexual health medicine in public sexual health centres in Australia and New Zealand $(n=93)$. The study period extended from 3 February to 4 April 2003 inclusive.

Results: 77 (83\%) fellows returned the questionnaire and, of these, 71 (76\%) were eligible for inclusion in the analysis. The median number of years of practising sexual health medicine was 16 (range 5-32) with $70 \%$ having worked in the field for 10 years or more. The generic questions that fellows asked most often concerned the presenting complaint/reason for attendance, the history of the presenting complaint, current sexual relationship status and last sexual contact, history of sexually transmitted infections (STIs), use of condoms during sexual intercourse in the past 3 months, and pattern (always, usually, sometimes, never) of condom use during that time period. The least frequently asked generic questions concerned age at first sexual activity, the number of sexual contacts, lifetime condom use, and hepatitis A status.

Conclusion: This study establishes the consistency and variability of sexual health information currently collected by fellows of the ACSHP when taking a history from a new client.
\end{abstract}

urrently, many countries, including Australia and New Zealand, are experiencing significant increases in a number of sexually transmitted infections (STIs). ${ }^{12} \mathrm{~A}$ central element to the control of STIs is accurate and timely surveillance data, both on the incidence of specific conditions and on behaviour. Sexual health clinics form an important part of a surveillance network and standardised collection of sexual health and lifestyle variables is a vital component of this. $^{2}$

This study seeks to document the degree of consistency or variability of the sexual history currently being collected by fellows of the Australasian College of Sexual Health Physicians (ACSHP) working in Australia and New Zealand. This will inform and contribute to uniform disease and behavioural data collection.

\section{METHODS}

The fellows of the ACSHP, actively involved in the practice of sexual health medicine in the public health setting during the period 3 February until 4 April 2003 in Australia and New Zealand were invited to participate in the study. Fellows were excluded from the analysis if they were working primarily in other areas of medicine (for example, gastroenterology) and not taking a sexual history on a routine basis. Fellows were asked to complete the questionnaire by recording how often they ask a particular question as part of the assessment of a new client attending a public sexual health centre.

The questionnaire was developed from clinic proformas from 23 clinics from every Australian state and territory and New Zealand. The questionnaire covered the client's sexual health history, sexual behaviour history, lifestyle and personal characteristics, characteristics of the client's partner(s), and the client's obstetric and gynaecological history (if female). In total, 40 questions were presented in the questionnaire. Some questions were presented in a stem and leaf format-for example, "What percentage of new clients do you ask about past STI(s)?.....if you do, do you document which STI(s)?" The scale for responses- $0 \%-\leqslant 5 \%-\leqslant 25 \%-$ $\leqslant 50 \%-\leqslant 75 \%-\leqslant 95 \%-\leqslant 100 \%$-was designed to identify the questions the fellows would ask "nearly always" or "always" ( $\leqslant 95 \%-\leqslant 100 \%$ of the time) and those that they would rarely ask ( $\leqslant 5 \%$ of the time) on a routine basis. The design of the stem and leaf questions was factored into the analysis by calculating the actual percentage the question was asked for the stem responses and the adjusted percentages for the leaf responses. Free format areas were included for fellows to add questions not covered in the questionnaire.

Questionnaires were posted from and returned to the office of the college. Questionnaires were numbered and matched to fellows. This matching remained confidential to the executive secretary of the college and was used only for the purposes of follow up if questionnaires were not returned by the specified time. Follow up took place at 3 and 6 weeks. All questionnaires were de-identified and forwarded to the researchers.

The study was approved by the Victorian Department of Human Services human research ethics committee and consent was obtained from each participant.

The questionnaire responses were entered into a secure database and descriptive analysis carried out using Excel and SPSS computer programs.

\section{RESULTS}

Seventy seven of the 93 (83\%) fellows returned questionnaires and $71(76 \%)$ questionnaires were eligible for inclusion in the analysis. Forty three of the 77 (56\%) fellows who responded were female. Fellows from all but one state/ territory responded.

The majority (41\%) of respondents had been fellows of the college for $1-5$ years, $32 \%$ had belonged for $6-10$ years, and $26 \% 11-15$ years. Forty seven per cent of fellows had entered the college through the grandfather clause, 39\% had gained fellowship through formal college training, and 14\% were individuals who had been invited into the college. 
Table 1 Questions asked by $70 \%$ or more fellows

\begin{tabular}{|c|c|c|}
\hline What percentage of new clients do you ask: & Actual \%* & $\%$ adjusted $t$ \\
\hline 1 about their presenting complaint/reason for visit? & 95 & 95 \\
\hline $\begin{array}{l}2 \text { if the patient is not pregnant or trying to become pregnant, about } \\
\text { contraception? (female) }\end{array}$ & 95 & 95 \\
\hline 3 the date of their last Pap smear? (female) & 94 & 94 \\
\hline 4 about their current sexual relationship status? & 94 & 94 \\
\hline 5 the result of their last Pap smear? (female) & 93 & 93 \\
\hline 6 if they have ever been pregnant? (female) & 92 & 92 \\
\hline 7 if they have used condoms in the past 3 months? & 92 & 92 \\
\hline $\begin{array}{l}8 \text { if they have used condoms, the pattern (always, sometimes) } \\
\text { of condom use in the past } 3 \text { months? }\end{array}$ & 91 & 91 \\
\hline 9 a history of the presenting complaint? & 96 & 91 \\
\hline 10 for a history of STI(s)? & 90 & 90 \\
\hline 11 about their last sexual contact? & 90 & 90 \\
\hline $\begin{array}{l}12 \text { if the have had any vaginal sex with any male partner(s) } \\
\text { in the past months? (female) }\end{array}$ & 90 & 90 \\
\hline 13 a history of abnormal Pap smears? (female) & 87 & 87 \\
\hline 14 if they have ever been pregnant, the number of pregnancies? (female) & 93 & 86 \\
\hline 15 if they have ever been pregnant, the number of live births? (female) & 92 & 85 \\
\hline $\begin{array}{l}16 \text { about the sex (opposite, same) of any sexual partner(s) in the past } \\
3 \text { months? }\end{array}$ & 85 & 85 \\
\hline $\begin{array}{l}17 \text { if they have had any vaginal sex with any female partner(s) in } \\
\text { the past } 3 \text { months? (male) }\end{array}$ & 85 & 85 \\
\hline 18 the date of their last menstrual period? (female) & 84 & 84 \\
\hline 19 if they have ever injected drugs? & 84 & 84 \\
\hline 20 about cigarette smoking? & 82 & 82 \\
\hline 21 about the number of sexual contacts in the past 3 months? & 82 & 82 \\
\hline $\begin{array}{l}22 \text { if they have used condoms, who (regular, casual partners) } \\
\text { they have used condoms with in the past } 3 \text { months? }\end{array}$ & 82 & 82 \\
\hline $\begin{array}{l}23 \text { if they have had any anal sex with any male partner(s) in the } \\
\text { past } 3 \text { months? (male) }\end{array}$ & 81 & 81 \\
\hline 24 which STI(s), if you take a history of STI(s)? & 94 & 81 \\
\hline 25 if they have ever been pregnant, about terminations? (female) & 87 & 81 \\
\hline 26 whether they have been previously tested for STIs, including HIV? & 80 & 80 \\
\hline 27 if they have ever been pregnant, about miscarriages? (female) & 86 & 79 \\
\hline 28 details of their menstrual cycle? (female) & 78 & 78 \\
\hline $\begin{array}{l}29 \text { about the sex (opposite, same) of any sexual partner(s) } \\
\text { in the past } 12 \text { months? }\end{array}$ & 78 & 78 \\
\hline 30 about alcohol consumption? & 77 & 77 \\
\hline $\begin{array}{l}31 \text { if they have had any oral sex with any male partner(s) in } \\
\text { the past } 3 \text { months?(male) }\end{array}$ & 77 & 77 \\
\hline 32 if they have used condoms in the past 12 months? & 76 & 76 \\
\hline 33 if they have ever injected drugs, if they are currently using drugs? & 91 & 75 \\
\hline $\begin{array}{l}34 \text { if they have had any vaginal sex with any male partner(s) in the } \\
\text { past } 12 \text { months? (female) }\end{array}$ & 74 & 74 \\
\hline $\begin{array}{l}35 \text { if they have used condoms in the past, the pattern (eg, always, } \\
\text { sometimes) of condom use in the past } 12 \text { months? }\end{array}$ & 74 & 74 \\
\hline 36 if they have ever injected drugs when they last injected? & 87 & 73 \\
\hline $\begin{array}{l}37 \text { if they have ever injected drugs, whether they have ever shared a } \\
\text { needle or syringe with another person? }\end{array}$ & 87 & 73 \\
\hline $\begin{array}{l}38 \text { if they have ever been pregnant, about any abnormal pregnancies? } \\
\text { (females) }\end{array}$ & 77 & 71 \\
\hline 39 if they have ever injected drugs and shared, when they last shared? & 85 & 71 \\
\hline 40 if they have ever been pregnant, about ectopic pregnancies? (female) & 76 & 70 \\
\hline 41 if they have ever used other ( non-injecting) drugs? & 70 & 70 \\
\hline
\end{tabular}

*Actual percentage is the percentage of sexual health physicians who would ask this question.

†Adjusted percentage is the actual percentage adjusted for the response in the stem part of the question.

The median number of years spent working in sexual health medicine was 16 (range 5-32); 70\% of fellows had at least 10 years' clinical experience, and the median number of clinical sessions/week was four (range 1-10).

The actual and adjusted percentages of the questions asked by the fellows are shown in table 1. Only those questions where $\geqslant 70 \%$ of fellows endorsed the question as current practice are shown. As can be seen in the table, the most commonly asked generic questions concerned the client's current situation-the presenting complaint/reason for attending the clinic, the history of the presenting complaint, current sexual relationship status and last sexual contact, history of STIs, use of condoms during sexual intercourse in the past 3 months, and the pattern-always, usually (greater than $50 \%$ of the time), sometimes (less than $50 \%$ ), never-of condom use during that time frame. The range of actual percentages was $26 \%$ to $95 \%$ and adjusted percentages $25 \%$ to $95 \%$. The generic questions that the fellows asked clients least frequently concerned their age at first intercourse, the number of sexual contacts and who they used condoms with (regular, casual partners) in their lifetime and their hepatitis A status.

\section{DISCUSSION}

This study has established current practice of fellows of the Australasian College of Sexual Health Physicians when taking a sexual history. To the authors' knowledge this is the first study to establish current practice for sexual history taking based on clinic proformas. This information contributes to the development of best practice guidelines in sexual health and improving the surveillance through sexual health centres in our region.

The strengths of this study lie in the fact that current practice was identified initially from clinic proformas, from which a questionnaire was generated and completed by fellows actively working in the area of sexual health 
medicine. The response rate to the questionnaire was high and broad geographical coverage of Australia and New Zealand was achieved. In addition, free format areas in the questionnaire accommodated additional questions fellows ask as part of their current practice.

The answers to some questions were relatively predictable but the answers to others provide valuable insights into questions that may be useful for routine surveillance. For example, over $90 \%$ of fellows asked about the presenting problem and recent history. However, it was also clear from this study that lifetime sexual partners and even those in the past 12 months are considerably less likely to be routinely collected than those in the last 3 months. This information will be useful, particularly for informing surveillance of behavioural data.

Studies in the United States and United Kingdom of current practice in sexual health history taking have been carried out in other areas of medicine-for example, gynaecology, ${ }^{3}$ and in the context of conditions such chronic renal disease ${ }^{4}$ and cystic fibrosis ${ }^{5}$ in adolescents or in specific conditions such as chronic prostatitis/chronic pelvic pain syndromes $^{6}$ in sexual health medicine. In addition, the current practice of asking a specific sexual health question (for example, sexual assault) ${ }^{7}$ has been studied in isolation but not in the context of an entire sexual history.

\section{ACKNOWLEDGEMENTS}

We thank fellows for completing and returning the questionnaire for this study. Special thanks are extended to David Bradford, the President of the College of Sexual Health Physicians at the time, for supporting this study and Jan Edwards and Ursula Barwick of the college administration whose commitment in assisting with the logistics of the study contributed significantly to the quality of this research.
RLT is in receipt of a National Health and Medical Research Council (NHMRC) Public Health Postgraduate (PhD) Scholarship, Grant Id: 209153.

\section{CONTRIBUTORS}

RLT, MKP, and CKF planned the study; RLT was responsible for the coordination of the study, recruitment of the subjects, data collection, and entry of data into a study database; RLT and CKF performed the statistical analysis; RLT, MKP and CKF wrote and edited the paper.

\section{Authors' affiliations}

R L Tideman, C K Fairley, The University of Melbourne, School of Population Health, Melbourne Sexual Health Centre 580 Swanston Street, Carlton, Victoria 3053, Australia

M K Pitts, Australian Research Centre in Sex, Health and Society, Latrobe University 215 Franklin Street, Melbourne, Victoria, 3000,

Australia

\section{REFERENCES}

1 Anon. Communicable diseases-Australia. Canberra, Australian Health Government, 2002 (www.health.gov.au/pubhth/cdi/cdihtml.htm).

2 Adler M. Sexual Health-Report finds sexual health service to be in shambles. (Editorial) BMJ 2003;327:62-3.

3 Anon. Taking a sexual history: the role of the nurse. Nursing Times 2002;98:39-41.

4 Hergenroeder AC, Brewer, eds. A survey of pediatric nephrologists on adolescent sexual health. Pediatr Nephrol 2001;16:57-60.

5 Sawyer SM, Tully MA, Colin AA. Reproductive and sexual health in males with cystic fibrosis: a case for health professional education and training. J Adolesc Health $2001 ; 28: 36-40$.

6 Luzzi GA, Bignall C, Mandal D, et al, British Co-operative Clinical Group. Chronic prostatitis/chronic pelvic pain syndrome: national survey of genitourinary medicine clinics. Int J STD AIDS 2002;13:416-19.

7 Hurst C, MacDonald J, Say J, et al. Routine questioning about non-consenting sex: a survey of practice in Australasian sexual health clinics. Int J STD AIDS 2003; 14:329-33. 